Brief Report

\title{
Coronavirus Disease (COVID-19): Handling Challenges in Kuwait
}

\author{
Janvier Gasana ${ }^{1, *(\mathbb{D})}$ and Maryam Shehab ${ }^{2}$ (D) \\ 1 Department of Environmental and Occupational Health, Faculty of Public Health, Kuwait University, \\ Hawalli, Kuwait, P.O. Box 24923, Safat 13110, Kuwait \\ 2 Follow-up \& Air Quality Monitoring Management, Environment Public Authority, 4th Ring Rd, \\ Shuwaikh Industrial 70050, Kuwait; marshehab@hotmail.com \\ * Correspondence: Janvier.Gasana@hsc.edu.kw
}

Received: 12 May 2020; Accepted: 26 May 2020;

First Version Published: 5 June 2020 (doi: 10.3390/sci2020040)

Second Version Published: 14 July 2020 (doi: 10.3390/sci2030055)

check for updates

Third Version Published: 11 August 2020 (doi: 10.3390/sci2030063)

\begin{abstract}
The world is currently facing a serious pandemic of coronavirus disease 2019 (COVID-19) which started in Wuhan, China, and was then transmitted rapidly to other countries. Countries applied different methods and procedures in an attempt to prevent or reduce and/or control the incidence of cases and manage existing ones. This paper discusses the methods and procedures applied by Kuwait to control this epidemic, and how effective they have been. The State of Kuwait followed WHO, European CDC, US CDC, and/or other countries' institutional guidelines, and is still working on containing the disease, given the rising number of cases among Kuwaitis returning from affected areas such as the UK and USA, and migrant workers who share the burden, given their living conditions.
\end{abstract}

Keywords: coronavirus; COVID-19; 2019-nCoV; novel (new) coronavirus; pandemic control

\section{Introduction}

Viral epidemics such as the severe acute respiratory syndrome coronavirus (SARS-CoV) [1], H1N1 swine flu [2], and Middle East respiratory syndrome coronavirus (MERS-CoV) [3] are continuing to emerge worldwide and threaten public health worldwide [4]; countries are currently facing the serious public health issue posed by a virus known as SARS-CoV-2 that causes Corona Virus Disease 2019 (COVID-19). Indeed, 27 human cases of viral pneumonia (7 of them seriously ill) were reported by the Wuhan Municipal Health Commission in China on 12 December 2019 [5,6]. The common exposure was detected in the Huanan Seafood Wholesale Market that sells, among other things, farm animals, bats, and snakes. It was first classified as "pneumonia of unknown etiology", before being found to be caused by the coronavirus (CoV) family. So, the virus was named SARS-CoV-2.

In the beginning, nobody was able to confirm person-to-person transmission; however, most of the cases were linked to the Huanan seafood market in China. Then, the number of cases continued to increase rapidly, and evidence of person-to-person transmission showed up in visitors diagnosed with COVID-19 who had visited Wuhan [7]. Through high-speed rail within China and international travel, the virus was quickly disseminated to all areas of China and a large number of countries in Asia, America, and Europe within a month of its discovery. In the first two months, multiple epidemiological assessments were conducted in these countries. In Iran, using GIS (Geographical Information Systems) to produce epidemiological maps of cases and incidence rates by province, Arab-Mazar et al. [8] showed that during the first 20 days of the epidemic, 7161 cases of COVID-19 were reported at a cumulative rate of 8.9 cases per 100,000 population, reaching 1234 cases by 6 March 2020; all provinces were affected, and at Qom, the first two cases were reported, confirming that COVID-19 
had arrived in Iran from China. Subsequently, confirmed cases in Saudi Arabia were imported from Iran and one from Iraq, and imported cases from Iran were diagnosed in Kuwait, Bahrain, Iraq, Oman and Qatar, and also in Georgia, Estonia, Belarus, and even New Zealand [9].

In February 2020, Dr. Tedros Adhanom Ghebreyesus, the General Director of the World Health Organization, announced that the disease was caused by the new coronavirus [4]. It has since spread to numerous other countries worldwide, making it a global health crisis or pandemic, with elderly people and those with certain underlying medical conditions at the highest risk [10].

Using a single method to rapidly control the epidemic has proved insufficient, such as isolating cases and tracing contacts, or using airport screening and travel suspensions [11-13]. Many countries including Kuwait have already imposed travel restrictions including flight suspensions, closing borders, and health screening, but these have had a limited effect in reducing and controlling the outbreak. However, combining these restrictions with other intervention methods, such as applying mild to severe quarantine measures (one of the principal methods to control the spread), and changing behaviours, is hoped to have a greater effect on reducing and limiting the epidemic with international cooperation [12,14]. WHO's overall strategy is to control the COVID-19 pandemic by slowing down transmission and reducing associated mortality, with the ultimate aim of reaching and maintaining a state of low-level or no transmission [15]. Most countries are in various stages of scaling up or down public health and social measures. The intensity of implementation of these measures that include the identification, testing, isolation and care for all cases, tracing and quarantine of all contacts, public health and social measures at individual and community levels, etc., varies, measured on the WHO transmission scenario of each country (1. No cases, 2. First cases, 3. Clusters of cases, or 4 . Community transmission).

The WHO-recommended public health measures include personal protective measures (hand hygiene, respiratory etiquette), environmental measures, physical distancing measures, and travel-related measures [14]. Physical distancing measures apply to individuals (e.g., isolation of cases and quarantine of contacts) or to communities, specific segments of the population, or to the population as whole. These measures are not mutually exclusive. Additional measures include movement restrictions, closures of schools and businesses, geographical area quarantines, and international travel restrictions. These are sometimes referred to as "lockdown" or "shutdown" measures.

Migrant workers who live in cramped and unhygienic living spaces can accelerate the community transmission of COVID-19, undermining efforts by the authorities to control the spread. For example, according to the Minister of Health in Kuwait [16], the living conditions and social habits of these people make them more prone to infection than others. Indeed, it is impossible for many migrant workers to implement the advice of local health authorities and WHO [15]. Newspapers report that their accommodation is too crowded, with perhaps 12 people living in a single room in a dilapidated building; they often lack soap, water, or hand sanitizer to clean their hands regularly, and are being neglected by their sponsors after losing their income. A study by Alkhamis et al. [17] that used temporal and spatiotemporal epidemic dynamics of COVID-19 in Kuwait showed a distinct spreading and clustering events within and between migrant workers and citizen-residents communities. This study found out also that densely populated areas and poor living conditions of migrant workers resulted in the highest number of significant spreading and clustering events within their communities.

Precautions are necessary during this outbreak, especially as no vaccine for COVID-19 is expected for at least a year [18]. The differences in the epidemiologic characteristics of SARS-CoV-2 and SARS-CoV-1 probably arise from other factors such as high viral loads in the upper respiratory tract and the potential for persons infected with SARS-CoV-2 to shed and transmit the virus while remaining asymptomatic $[3,6]$. Should public health professionals assume then that every person in community or healthcare settings where COVID-19 cases are found can potentially spread the virus? In this case, everyone should wear a mask if they are in contact with other people.

Given the fact that COVID-19 is different from other viral infectious diseases, Ferguson et al. [19] described two possible fundamental strategies: suppression and mitigation. Suppression aims at 
reducing the reproduction number (the average number of secondary cases each case generates), $\mathrm{R}$, to below 1 and hence to reduce case numbers to low levels or (as for SARS or Ebola) eliminate human-to-human transmission. Mitigation aims at using non-pharmaceutical interventions (NPIs) (but with vaccines or drugs, if available), not to interrupt transmission completely, but to reduce the impact of the epidemic; this is akin to the strategy adopted by some US cities in 1918, and by the world more generally in the 1957, 1968 and 2009 influenza pandemics. In mitigation, population immunity builds up as the epidemic spreads, leading to an eventual rapid decline in case numbers and transmission dropping to low levels. So, the strategies differ in whether they aim to reduce $\mathrm{R}$ to below 1 (suppression), causing case numbers to decline, or to merely slow the spread by reducing $R$, but not to below 1 (mitigation). In the (unlikely) absence of any control measures or spontaneous changes in individual behaviour, [19] would expect a peak in mortality (daily deaths) to occur after approximately three months. In such scenarios, given an estimated R of 2.4 , they predicted $81 \%$ of the UK and US populations would be infected over the course of the epidemic.

The aim of the study is to discuss the procedures that are being used by Kuwait in controlling the epidemic and their effectiveness.

\section{Procedures Followed in Kuwait}

A review of existin data in Kuwait was used to summarize the precautions and procedures taken in the State of Kuwait during the outbreak.

According to updates from the Ministry of Health [20], the first day on which coronavirus cases were detected in Kuwait was 24 February 2020, with five cases; the number then increased day by day until 17 cases were recorded on 27 February, although on the following day only two cases were recorded, and after that, on some days, no cases at all. The highest number of recorded cases, 20, was on the 13 March, and on that day, the government announced a holiday for all employees in Kuwait in order to limit human contact, and hence, reduce and eliminate the incidence of cases from airborne person-to-person transmission. On the following day, four new cases were reported, with two in a critical condition, and on 22 March, 12 cases were reported, bringing the total in Kuwait to 188, five of them in a critical condition. The number of cases continues to fluctuate; this may be due to some people still going outdoors, not using hygiene products, or gathering indoors to attend social events.

According to the Ministry of Health's spokesperson [20], the strategy to control the COVID-19 pandemic in Kuwait follows the WHO-recommended procedures at three levels. The first covers the stages of transmission: 1 . no cases; 2 . first cases from Iran; 3 . cluster of cases among migrant workers; and 4. community transmission, the current situation. The second level includes procedures that are specific to Kuwait, such as in the case of migrant workers; for migrant workers in factories, the Public Authority for Industry, in coordination with government agencies and the private sector, allowed employers to temporarily accommodate them for a period of six months within the limits of those factories or adjacent sites. Also, Kuwait Airport has been using thermal cameras to detect any suspected coronavirus cases from abroad. The third level comprises additional measures, with public health and social measures that include lockdown and curfew.

At the third level, the government introduced the following procedures and precautions (Figure 1) to control transmission of the virus:

1. Study in all schools and universities was postponed for two weeks, starting at the beginning of March, then extended for two weeks. The end of February was already a holiday, including the 25-26 February National Day and Liberation Day celebrations, marking the end of the Iraqi invasion. By April 17, 2020, students were still at home.

2. All employees received a paid holiday for two weeks from 12 to 28 March, extended to 26 April, except for staff in the medical sector, civil aviation, fire stations, the Ministry of the Interior, Kuwait Municipality, the Ministry of Electricity, the Ministry of Public Works and Water, and the Ministry of Commerce and Industry.

3. All flights to and from Kuwait were cancelled until further notice. 
4. Gatherings in public places including malls, restaurants and mosques were banned.

5. All malls were closed from the 14th of March, 2020 for two weeks.

6. All people have been instructed not to leave home unless necessary.

7. Suspected cases among those who entered Kuwait before flights were cancelled and who did not have coronavirus symptoms have been isolated in their homes for two weeks; after taking samples (swabs from tongue and nose); if diagnosed with the disease, they are sent immediately to one of Kuwait's hospitals and isolated for treatment, while household members in contact with the patient are also asked to go to hospital for tests.

8. Free sanitizers have been provided and gloves are to be worn in public places such as grocery shops and ATMs in banks, including drive-through ones.

9. Fake news and rumours about the new coronavirus are being detected and managed by taking maximum action against them, as they can cause fear in society, weaken the state's prestige, and/or disrupt public order.

10. Awareness is being spread on media and social media, including key information on dealing with the outbreak, precautions, and how to manage behaviour and mental health (e.g., stress, anxiety, anger) caused by the disease events and news.

11. A partial curfew was applied from 22 March from 17:00 to 4:00, and extended to 6:00 on 7 April.

12. Lockdown of Jleeb and Mahboula from the $6^{\text {th }}$ of April, 2020 (with the hope that this would flatten the pandemic curve).

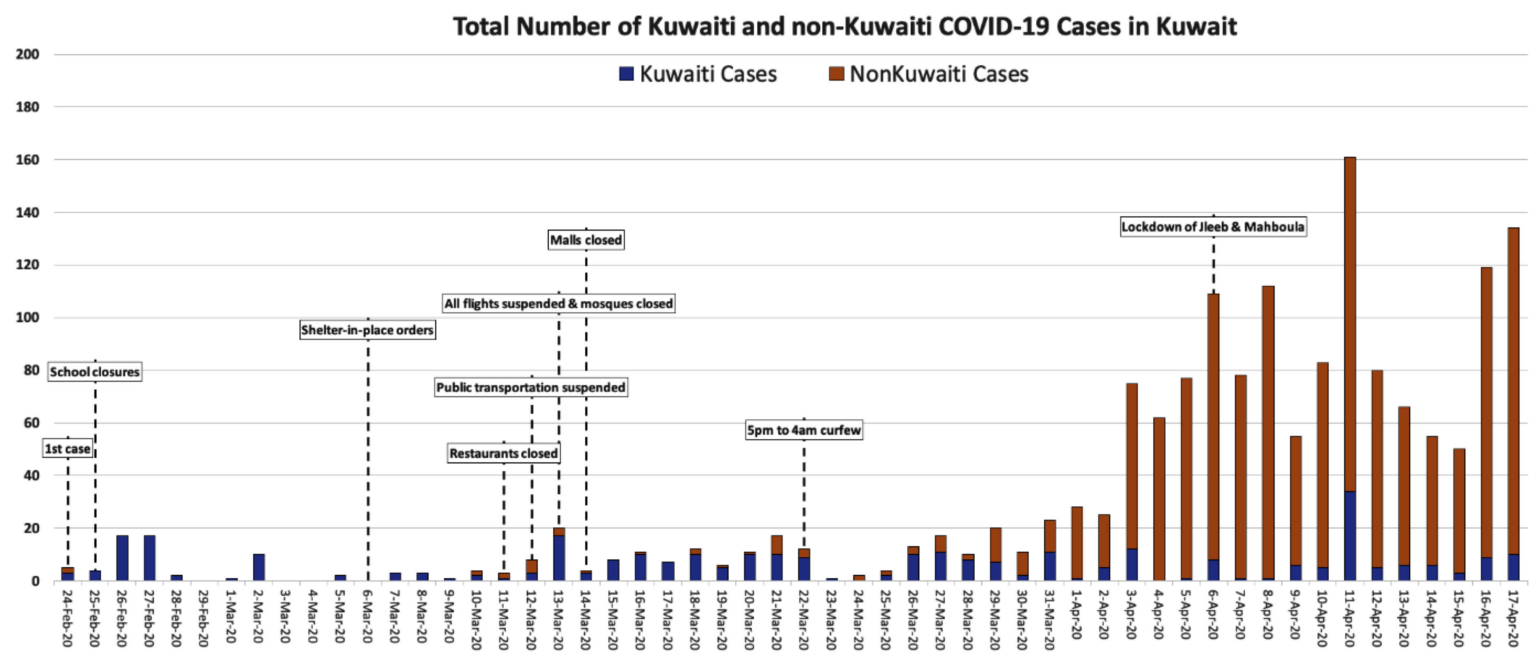

Figure 1. Total Number of Kuwaiti and Non-Kuwaiti COVID-19 Cases and Control Strategies in Kuwait between 28th of February and 17th of April, 2020 (Data Source: MOH, 2020).

Penalties have been announced for anyone caught breaking the coronavirus curfew in Kuwait. They will be jailed for up to three years and fined 10,000 Kuwaiti dinars $(\$ 32,000)$, in line with the new laws reported by the country's deputy prime minister on Sunday 22 March. The lockdown was decided as part of stricter government measures to control the spread of the coronavirus, including the partial curfew until further notice and extending the closure of all state institutions until 26 April.

Currently, the Ministry of Health is calling upon recovered cases for blood donations, to obtain the plasma from their blood to cure current patients. This has been shown to be an effective treatment tested and applied successfully in some countries, including China, France, Philippines, Italy and USA.

As shown in the Ebola outbreak, infections and deaths in health care settings could be easily prevented with adequate knowledge and training of the PPE (personal protective equipment) that represent useful preventive measures [21]. In this COVID-19 pandemic, as Cook [22] said, "PPE is a current hot topic, probably the most talked about and emotive subject for front-line healthcare staff working with patients with coronavirus disease (COVID-19)". He pointed out that there are two main 
related problems: shortages of equipment; and inappropriate use of equipment, which are common in most countries including Kuwait.

\section{Discussion}

As countries worldwide are still dealing with the pandemic, Kuwait has taken effective procedures and measures to control and limit the incidence of the disease, with the aim of completely eliminating it. These procedures and methods were set gradually, as outlined above, starting from using thermal cameras in airports to detect suspected cases in order to isolate and treat them.

Tools of molecular biology diagnosis of symptomatic/asymptomatic contacts are being utilized for people coming from abroad, people who feel sick and have fever, and people who have been in direct contact with an infected person [20]. In addition, Kuwait has now introduced a phone app for contact tracing. There are now FDA (US Food and Drug Administration)-approved tests, used in rapid "point-of-care" COVID-19 detection. The tests, using molecular methods, make it possible to detect the coronavirus within 45 minutes.

Although thermal cameras have helped in detecting suspected coronavirus cases, this method is insufficient on its own, and should be combined with other methods and technologies for more effective, accurate and comprehensive information, to support better risk management and decision making $[1,23,24]$. Kuwait has since implemented more methods to reduce and control the disease, which resulted in a significant decrease in the diagnosed cases (i.e., after the national holiday). The government effectively instituted public health and social measures that include personal protective measures (hand washing, the use of a cloth face mask before entering any grocery store), environmental measures, physical distancing measures, and travel-related measures.

During April the number of recorded cases fluctuated, but did not reach a new peak until a maximum of daily cases of 161 on 11 April. Figure 1 shows that as of 16 April 2020, Kuwait had 1,405 cases, 225 recovered and 3 deaths [20]. Indeed, the Kuwaiti Ministry of Health announced that 161 people had been infected in just 24 hours [16]. They added that 127 cases were found among people who were with infected patients (4 Kuwaiti citizens, 101 Indian residents, 15 Bengali, one Saudi, one Filipino, one Jordanian, and one Pakistani), through community transmission; the majority were high-risk migrant workers and the rest were travel-related cases.

Figure 2 shows the daily COVID-19 cases in Kuwait by source, indicating a decrease from the 11 April peak. Indeed, the first cases came from Iran, followed by cases from other countries including USA and UK, and the cases through community transmission involving migrant workers. Targeted intervention measures within migrant workers' communities in Kuwait substantially lowered the magnitude and the number of spreading and clustering events respectively [17].

As of 17 April, out of 1658 cases reported by the Ministry of Health's Media Office, Indian expatriates represented $55.7 \%$ of cases (924)), while Kuwaiti cases were $19.7 \%$ (327), followed by Bangladeshi 7.7\% (128), Egyptian 6.6\% (109) along with expatriates from other countries with fewer cases (see Figure 3). Figure 4 shows that three weeks after April 17, 2020 (by the 11 ${ }^{\text {th }}$ of May, 2020), on a global COVID-19 trajectory, USA was at the top and Kuwait at the bottom. Kuwait's counter-measures and strategies, with only 65 deaths, are clearly more effective than those in the USA, and in the European countries. Indeed, the country was praised by WHO in this regard since in the Middle East, Kuwait was also more successful than neighboring countries. 


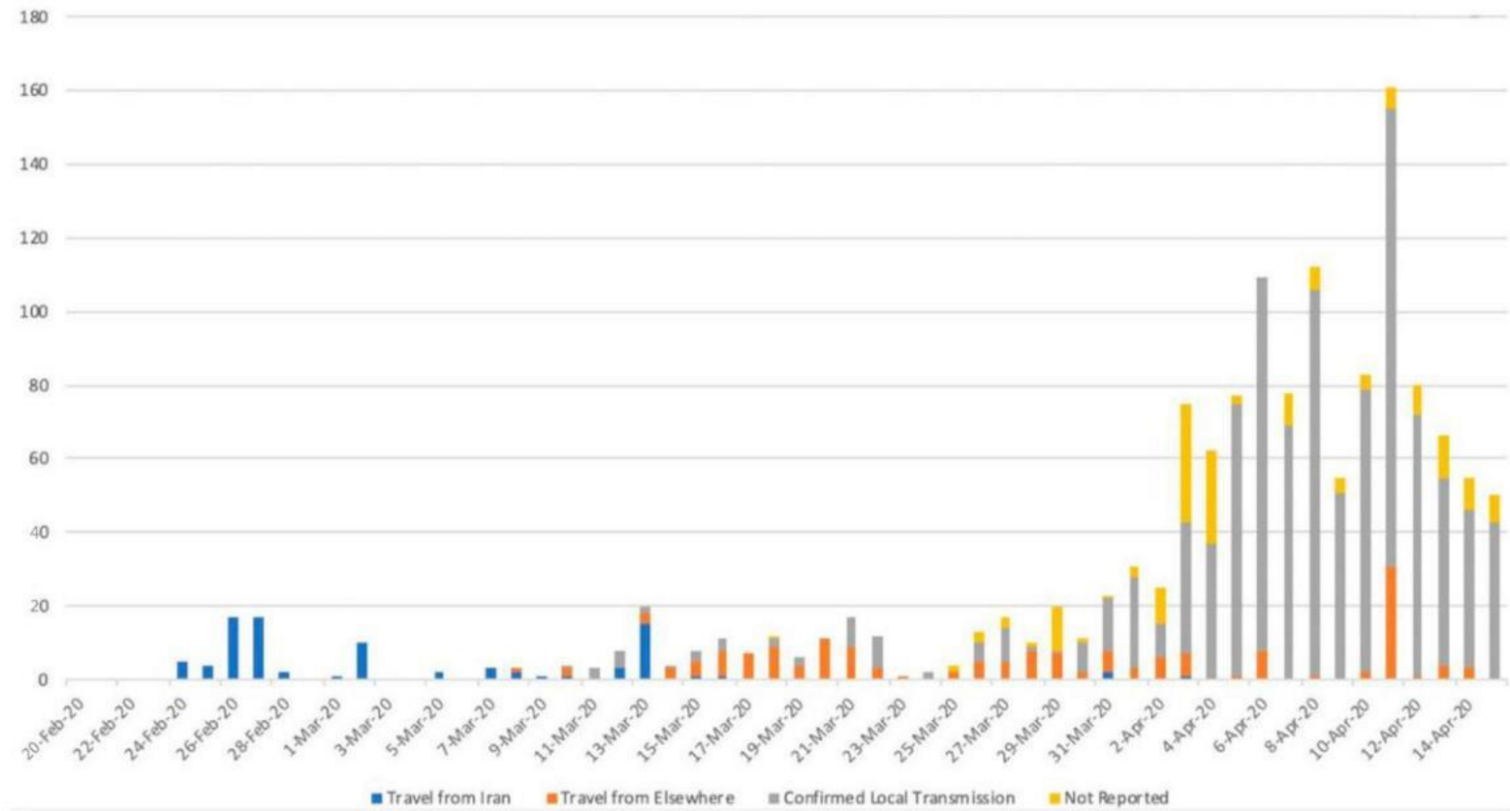

Figure 2. Daily COVID-19 Cases in Kuwait by Source (Source: MOH, 2020).

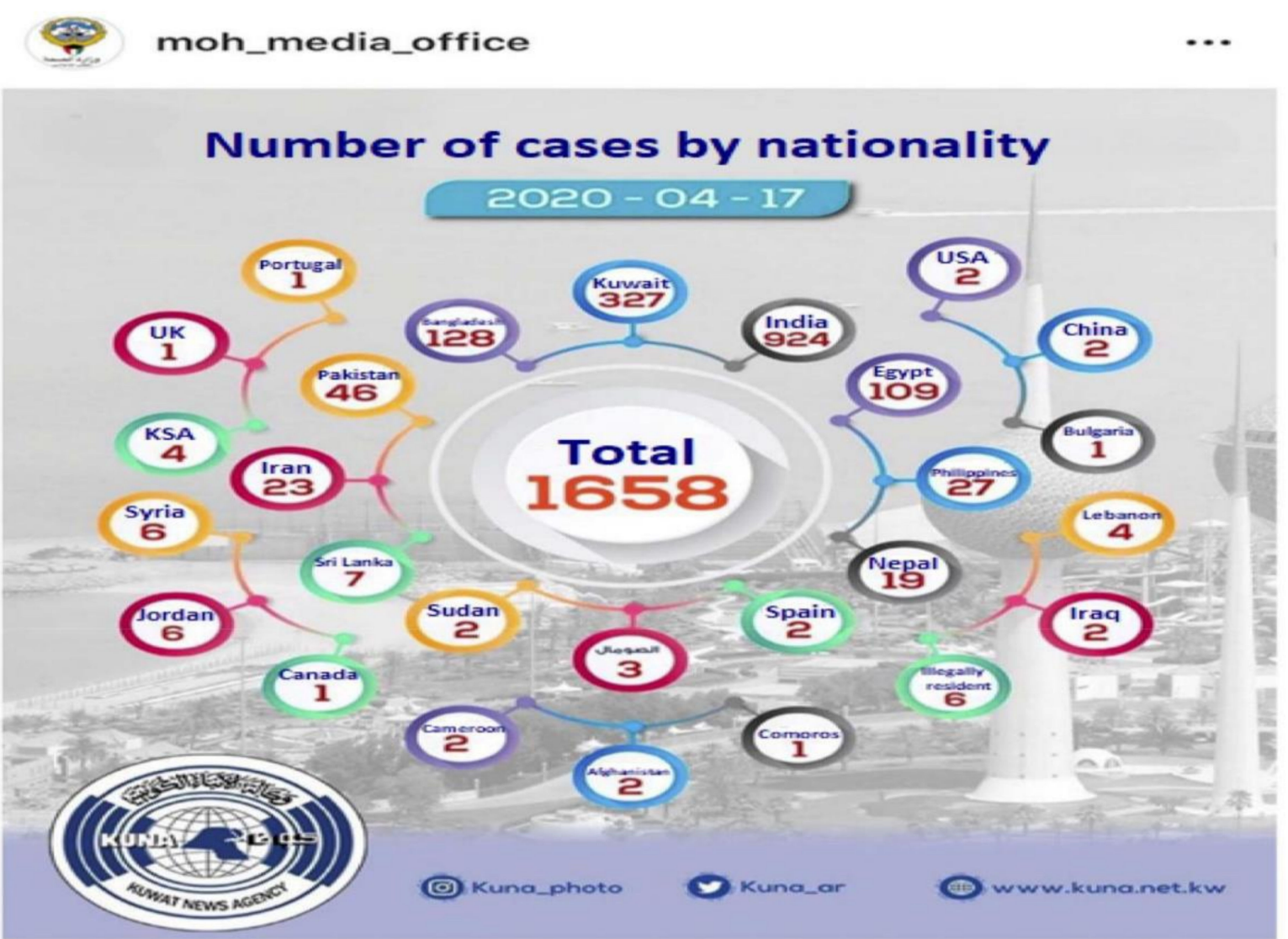

Figure 3. Breakdown of COVID-19 Cases by Nationality in Kuwait. Source: KUNA Report on Ministry.of Health Media Office (17 April 2020). 


\section{DAILY COVID19 CASES IN KUWAIT ACCORDING TO SOURCE}

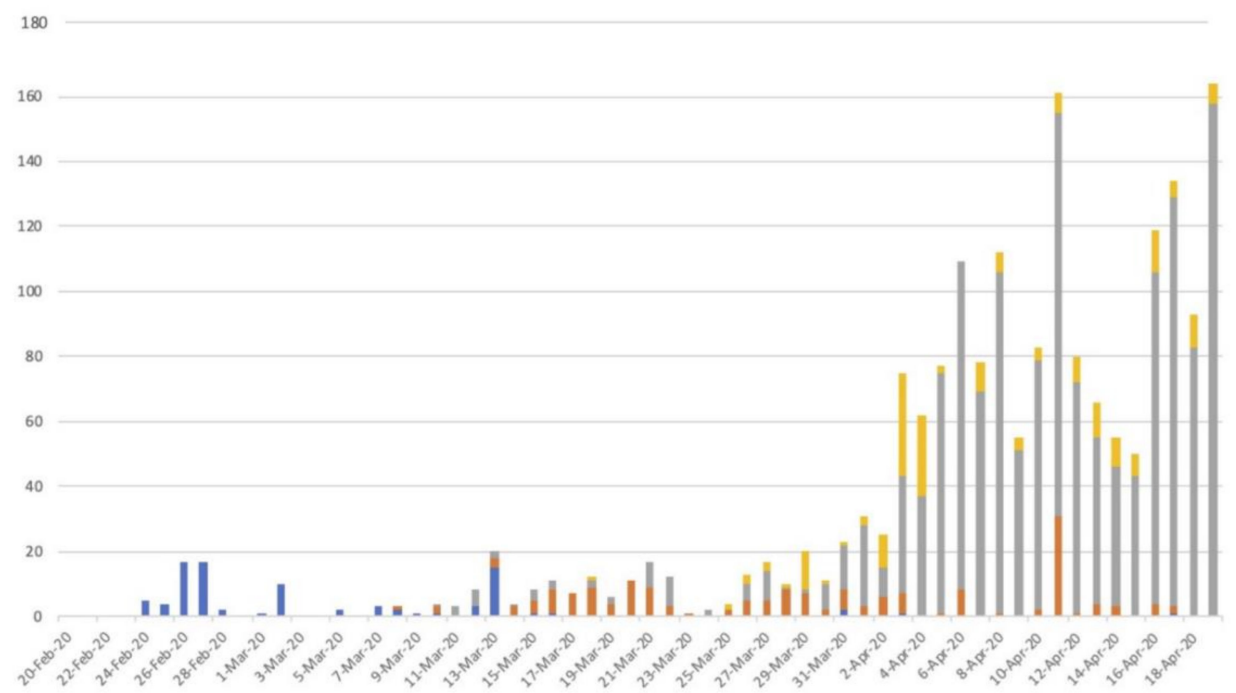

COVID19 Case Trajectory Across Multiple Countries

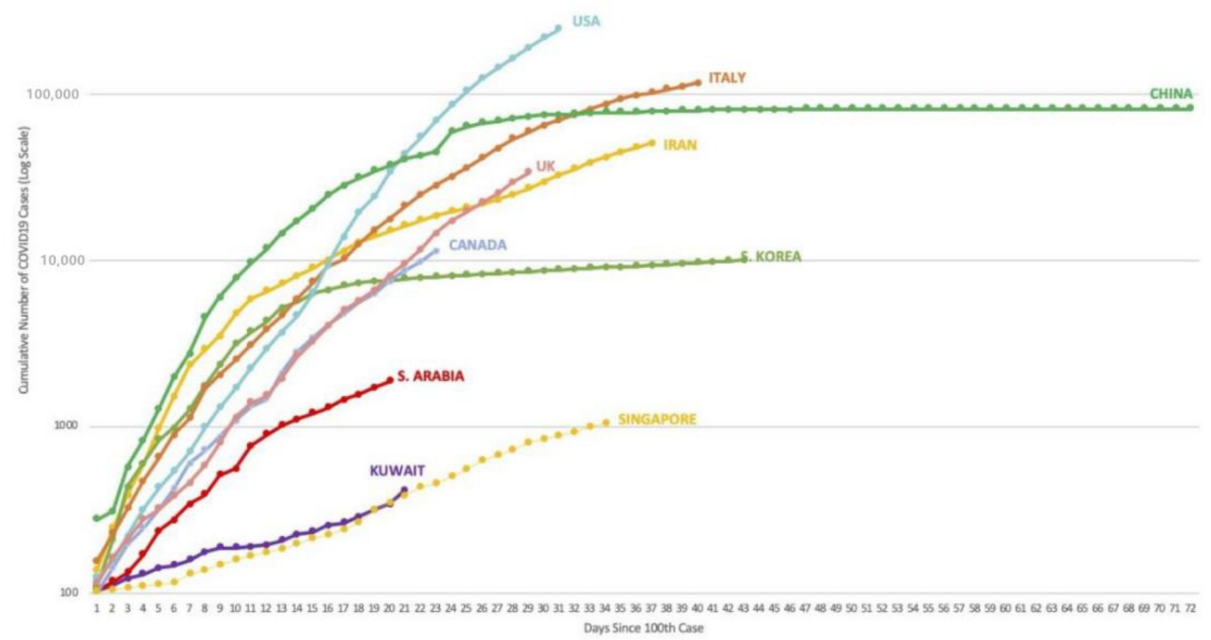

Figure 4. Kuwait Daily COVID-19 Cases and Global COVID-19 Trajectory (Source: MOH, 2020).

\section{Conclusions}

The State of Kuwait has cooperated on both the national and international levels to reduce and control COVID-19 by applying a combination of methods and procedures to overcome this epidemic. However, this does not mean that the problem is solved, nor can continuing reductions in case numbers and eliminating the disease in Kuwait be guaranteed. These methods and procedures need to be applied over a longer period, not only in Kuwait, but also worldwide, adding further new effective methods and procedures as they become available, especially should an effective vaccine be developed and deployed. Kuwait's strategies are working better than in the Gulf countries, USA, and European countries. As this point, Kuwait is dealing with two major sources of coronavirus, that is, Kuwaitis returning from affected countries such as the UK and USA, and migrant workers, most of whom are Indians, due to their cramped living conditions. Indeed, Alkhamis et al. [17] pointed out the importance of maintaining migrant workers' health and living conditions in limiting the transmission of COVID-19 in Kuwait. A high contact rate among the population in Kuwait implies that the epidemic peak 
value is yet to be reached and that more strict intervention measures must be incorporated [25]. If all nations manage their cases correctly, we should see the end of the pandemic soon. However, if the WHO-recommended public health and social measures (listed below) are not strictly followed by all affected countries, we will keep losing lives.

The best public health measures that have been suggested by WHO and other public health organizations include, but are not limited to, the following:

1. Wash one's hands frequently

2. Maintain social distancing (2 $\mathrm{m}$ or $6 \mathrm{feet})$

3. Avoid touching one's eyes, nose, and mouth

4. Practice respiratory hygiene

5. If one has a fever, cough, and difficulty breathing, seek medical care early

6. Staff informed and follow advice given by healthcare providers

7. Commit to the curfew hours and stay at home [20].

8. Wear a mask [Indeed, according to CDC [26], recent studies show that a significant portion of individuals with coronavirus lack symptoms ("asymptomatic"), and that even those who eventually develop symptoms ("presymptomatic") can transmit the virus to others before showing symptoms. This means that the virus can spread between people interacting in close proximity-for example, speaking, coughing, or sneezing-even if those people are not exhibiting symptoms. In light of this new evidence, the CDC recommends wearing cloth face coverings in public settings where other social distancing measures are difficult to maintain (e.g., grocery stores and pharmacies), especially in areas of significant community-based transmission)].

Author Contributions: Conceptualization, M.S. and J.G.; methodology, M.S. and J.G.; writing-original draft preparation, M.S.; writing-review and editing, J.G. These authors contributed equally to this work. All authors have read and agreed to the published version of the manuscript.

Funding: This research received no external funding.

Conflicts of Interest: The authors declare no conflict of interest.

\section{References}

1. Allam, Z.; Jones, D.S. On the Coronavirus (COVID-19) Outbreak and the Smart City Network: Universal Data Sharing Standards Coupled with Artificial Intelligence (AI) to Benefit Urban Health Monitoring and Management. Healthcare 2020, 8, 46. [CrossRef] [PubMed]

2. AlQabas. World Health Organization Praises Kuwaiti Actions in Facing Corona. Available online: https: //alqabas.com/article/5755810 (accessed on 18 April 2020).

3. Bai, Y.; Yao, L.; Wei, T.; Tian, F.; Jin, D.Y.; Chen, L.; Wang, M. Presumed asymptomatic carrier transmission of COVID-19. JAMA 2020, 323, 1406-1407. [CrossRef] [PubMed]

4. Cascella, M.; Rajnik, M.; Cuomo, A.; Dulebohn, S.C.; Di Napoli, R. Features, Evaluation and Treatment Coronavirus (COVID-19); StatPearls Publishing LLC.: Treasure Island, FL, USA, 2020.

5. Lu, H.; Stratton, C.W.; Tang, Y.W. Outbreak of pneumonia of unknown etiology in wuhan China: The mystery and the miracle. J. Med. Virol. 2020, 92, 401-402. [CrossRef] [PubMed]

6. Zou, L.; Ruan, F.; Huang, M.; Liang, L.; Huang, H.; Hong, Z.; Yu, J.; Kang, M.; Song, Y.; Xia, J.; et al. SARS-CoV-2 viral load in upper respiratory specimens of infected patients. N. Engl. J. Med. 2020, 382, 1177-1179. [CrossRef] [PubMed]

7. Centers for Disease Control and Prevention (CDC). Available online: https://www.cdc.gov/media/release/ \%202020/p0130-coronavirus-spread.html (accessed on 12 May 2020).

8. Arab-Mazar, Z.; Rabaan, A.; Sah, R.; Dhama, K. Mapping the incidence of the COVID-19 hospot in Iran-Implications for Travellers. Travel Med. Infect. Dis. 2020, 34, 101630. [CrossRef] [PubMed]

9. Wilson, M.E.; Chen, L.H. Travelers give wing to novel coronavirus (2019-nCoV). J. Trav. Med. 2020, 27, taaa015. [CrossRef] 
10. Wang, W.; Tang, J.; Wei, F. Updated understanding of the outbreak of 2019 novel coronavirus (2019-nCoV) in Wuhan, China. J. Med. Virol. 2020, 92, 441-447. [CrossRef]

11. Hellewell, J.; Abbott, S.; Gimma, A.; Bosse, N.I.; Jarvis, C.I.; Russell, T.W.; Munday, J.D.; Kucharski, A.J.; Edmunds, W.J.; Funk, S.; et al. Feasibility of controlling COVID-19 outbreaks by isolation of cases and contacts. Lancet Glob. Health 2020, 8, 488-496. [CrossRef]

12. Chinazzi, M.; Davis, J.T.; Ajelli, M.; Gioannini, C.; Litvinova, M.; Merler, S.; Pastore, Y.P.A.; Mu, K.; Rossi, L.; Sun, K.; et al. The e ect of travel restrictions on the spread of the 2019 novel coronavirus (COVID-19) outbreak. Science 2020, 368, 395-400. [PubMed]

13. Quilty, B.J.; Cli ord, S.; Flasche, S.; Eggo, R.M. Effectiveness of airport screening at detecting travellers infected with novel coronavirus (2019-nCoV). Eurosurveillance 2020, 25, 2000080. [CrossRef] [PubMed]

14. Fang, Y.; Nie, Y.; Penny, M. Transmission dynamics of the COVID-19 outbreak and effectiveness of government interventions: A data-driven analysis. J. Med. Virol. 2020, 92, 645-659. [CrossRef] [PubMed]

15. WHO. Considerations in Adjusting Public Health and Social Measures in the Context of COVID-19 Interim Guidance. Available online: WHO/2019-nCoV/Adjusting-PH-measures/2020.1 (accessed on 18 April 2020).

16. KUNA. Fight against Coronavirus in Two Hotspots in Kuwait to Take Weeks. Available online: https: //news.Kuwaittimes.net (accessed on 18 April 2020).

17. Alkhamis, M.A.; Al Youha, S.; Khajah, M.M.; Haider, N.B.; Alhardan, S.; Nabeel, A.; Al Mazeedi, S.; Al-Sabah, S.K. Spatiotemporal Dynamics of COVID-19 epidemic in the State of Kuwait. Int. J. Infect. Dis. IJID 2020, 98, 153-160. [CrossRef] [PubMed]

18. Kaplan, E.H. Containing 2019-nCoV (Wuhan) coronavirus. Health Care Manag. Sci. 2020, 395, 497-506. [CrossRef] [PubMed]

19. Ferguson, N.; Laydon, D.; Nedjati Gilani, G.; Imai, N.; Ainslie, K.; Baguelin, M.; Bhatia, S.; Boonyasiri, A.; Cucunuba Perez, Z.; Cuomo-Dannenburg, G.; et al. Impact of non-pharmaceutical interventions (NPIs) to reduce COVID-19 mortality and healthcare demand. Bull. Math. Biol. 2020.

20. MOH. COVID 19 Updates. Available online: https://corona.e.gov.kw/En/ (accessed on 16 April 2020).

21. Troiano, G.; Nante, N. Political and medical role in the last Ebola outbreak. J. Prev. Med. Hyg. 2017, 58, 201-202.

22. Cook, T.M. Personal protective equipment during the coronavirus disease 2019 (COVID-19) pandemic-A narrative review. Anaesthesia 2020, 75, 920-927. [CrossRef] [PubMed]

23. Boulos, M.N.K.; Peng, G.; Vopham, T. An overview of GeoAI applications in health and healthcare. Int. J. Health Geogr. 2019, 18, 7. [CrossRef] [PubMed]

24. Boulos, M.N.K.; Geraghty, E.M. Geographical tracking and mapping of coronavirus disease COVID-19/severe acute respiratory syndrome coronavirus 2 (SARS-CoV-2) epidemic and associated events around the world: How 21st century GIS technologies are supporting the global fight against outbreaks and epidemics. Int. J. Health Geogr. 2020, 19, 8.

25. Almeshal, A.M.; Almazrouee, A.T.; Alenizi, M.R.; Alhajeri, S.N. Forecasting Spread of COVID-19 in Kuwait. Appl. Sci. 2020, 10, 3402. [CrossRef]

26. Centers for Disease Control and Prevention (CDC). Recommendations Regarding the Use of Cloth Face Coverings, Especially in Areas of Significant Community-Based Transmission. Available online: https: //www.cdc.gov/coronavirus/2019-ncov/prevent-getting-sick/cloth-face-cover.html (accessed on 19 April 2020).

(C) 2020 by the authors. Licensee MDPI, Basel, Switzerland. This article is an open access article distributed under the terms and conditions of the Creative Commons Attribution (CC BY) license (http://creativecommons.org/licenses/by/4.0/). 